\title{
Teaching Exploration of Circuit Theory Course Based on Improving the Innovative Ability
}

\author{
Sun Bo \\ School of Automation and Electrical Engineering \\ Shenyang Ligong University \\ Shenyang, China \\ e-mail:sunbeer888@163com
}

\author{
Chen Gang* \\ School of Automation and Electrical Engineering \\ Shenyang Ligong University \\ Shenyang, China \\ e-mail:sunruipeng9402@163.com
}

\begin{abstract}
- the circuit course is a first professional basic course for electrical majors with a connecting role. According to the characteristics of the circuit theory course, less class hours, and students' basic differences, the teaching reform program of the circuit theory course teaching methods based on improving the innovation ability is put forward. In here, the circuit teaching is divided into four steps: basic knowledge, basic theory, basic circuit form and analysis method, and extension theory. The teaching method of cultivating creative thinking ability, the teaching method of training engineering practice ability and the image thinking teaching method are combined. Through the analysis of three kinds of basic circuit forms, the ability of students' engineering practice is cultivated. Through the discussion of the relationship between the various parts of the circuit theory, students' creative thinking ability is trained. Take students as the main body, guide them to form the habit of exploring knowledge, develop scientific thinking method, and cultivate engineering quality.
\end{abstract}

Keywords-circuit theory; teaching exploration; innovative ability; engineering quality

\section{INTRODUCTION}

The circuit course is the first professional basic course of electric specialty. In order to analyze the electromagnetic phenomenon in the circuit, the basic rules and analysis method for circuit are the main contents of circuit course. At present, in order to realize the goal of engineering quality education, and improve the students' ability of innovation and engineering practice, each profession has increased the experimental hours and compressed theory teaching hours. The theoretical teaching hours of circuit course is reduced from 96 to 64, while there is no big change in teaching content In order to transfer the knowledge of circuit theory to the students in the limited teaching hours, help students better grasp the basic knowledge of the circuit, develop students' ability to apply circuit knowledge into engineering practice, and train students' innovative thinking ability, the teaching reform program of the teaching exploration of circuit theory course based on improving the innovative ability has been put forward. In the teaching of circuit theory, the four-step teaching method has been applied, the student-centered teaching mode has been adopted, the flexible and diverse teaching method and the various forms teaching measure has been used. In the process of teaching, should pay attention to

Fund Project: Research project of undergraduate education and teaching reform in Colleges and universities in Liaoning Province, No.UPRP20140443.

*Correspondence author: Chen Gang stimulate students' interest in learning, mobilize the enthusiasm of learning, make the students master the circuit theory step by step, cultivate students' ability of engineering practice, and train innovative thinking ability.

\section{OVERALL FRAMEWORK OF CIRCUIT CONTENT}

The circuit course textbook is compiled by Mr. Qiu Guanyuan's “circuit”. Based on analyzing the knowledge structure and teaching goal, the course content is optimized and is divided into four parts. There are basic knowledge, basic theory, three kinds of basic circuit forms and analysis, extension theory. Their relations are shown in Fig. 1.

Among them, the basic knowledge is the foundation of the whole circuit theory, the basic theory is the key content, the three kinds of basic circuit forms and their analysis are difficult part, and the expansion theory is the improvement content. According to the relationship between the four parts, the next step of the teaching content to be begun after the premise of mastering the corresponding knowledge.

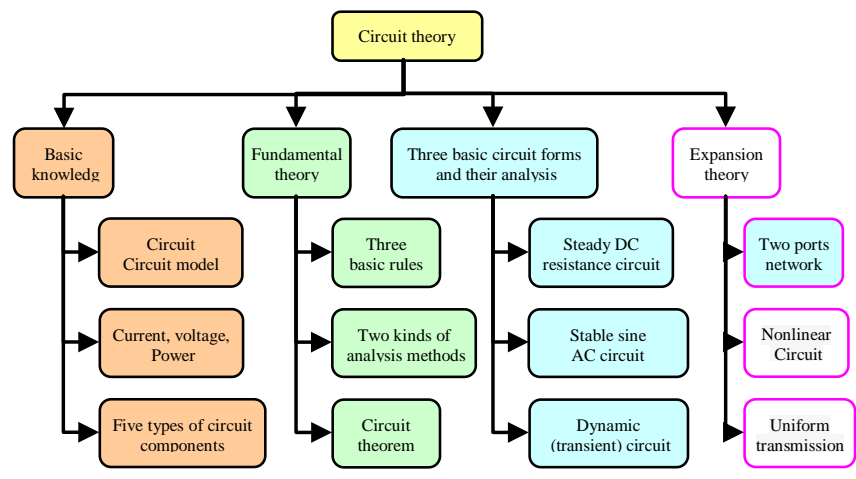

Fig. 1. The overall framework of the circuit content

\section{TEACHING OF "FOUR STEPS"}

According to the basic content of circuit theory, the theoretical teaching is carried out with the "four step" teaching method step by step.

In the part of basic knowledge, these knowledge points, there are the concept and application of the reference direction of current and voltage, and of the controlled source components, are difficult for many students to understand. 
Through illustrating specific examples, homework exercises, and repeated practice so that there concepts is easy to understand and the application to concept is also handy.

The three basic laws of the basic theory are Ohm's law, Kirchhoff's law, and the linear superposition theorem. These laws are the axioms in the circuit theory, and do not need to prove, but must be combined with the basic understanding of students to the natural phenomenon to explain. Two kinds of analysis methods are the equivalent transformation method and the network equation method. In that, the equivalent transformation method refers to the resistance in series or parallel and its equivalent transform, $\mathrm{Y}$ or $\Delta$ resistor and its equivalent conversion, the two form of power model and its equivalent transformation and equivalent resistance, the network equation method refers to branch current method, mesh current method, loop current method and node voltage method. These methods should be explained in detail and repeated practice in the analysis of the steady DC resistance circuit, and them are applied to the phase analysis method of stable sine AC circuit and the complex frequency domain analysis of dynamic circuits. Circuit theorem refers to substitution theorem, Thevenin's theorem and Norton's theorem, maximum power-transmitting theorem, Tellegren's theorem and duality principle. These theorems should be explained in combination with the analysis method of the steady DC resistance circuit.

The three basic circuit forms refers to steady DC resistance circuit, the stable sine AC circuit and dynamic (transient) circuit. Their analysis methods are systematic, logic relation, and the steady DC resistance circuit analysis is the foundation.

The two port network in the expansion theory is the improvement of circuit theory. It is based on the other three parts, at the same time can deepen the understanding of knowledge.

\section{FleXiBle TEACHING MEthods}

\section{A. Image thinking teaching method}

The circuit course has the characteristics of strong system, more contents and less time. In the teaching process, when deriving some important formulas or explaining some important example to students, the traditional teaching mode of writing on the blackboard can help teachers to control the teaching progress and to adjust the teaching depth according to the student's actual ability, so as to strengthen the interactive communication between teachers and students. For some abstract concepts and difficult to understand theorem, a new method by using the computer multimedia technology to assist teaching is used to improve teaching quality. The laborious and time-consuming writing content will be shown with rich and colorful graphics even lively animation, so the invisible becomes visible and the abstract becomes intuitive, these can bring the boring and complicated circuit theory to life and make the students have a perceptual knowledge for the dry circuit, can recall students' attention, invoke students' enthusiasm, cultivate students' interest of learning effectively and make students obtain knowledge and wisdom in a pleasant surroundings.
For example, on the teaching of linear superposition theorem, can indicate the separate action of each independent source with the light and dark lines, at the same time, indicate the response of each independent source when it is used alone by using different colors, so that make the students understand the theorem more intuitive and more impressive.

When study on frequency characteristics of passive filter, using electronic simulation software (such as PSPICE, MULTISIM or ORCAD), make teachers and students in the experimental environment, can easily change the parameters of capacitance or inductance values of circuit elements, quickly give the frequency characteristic curve of the filter and its change. The explanation of theory has been carried out along with the demonstration of simulation experiment, the results of the simulation experiments are compared with the theory, so that students will be able to feel the practice and application for circuit theory in the classroom, and then have a preliminary understanding of the engineering practice. This kind of electronic simulation software should be introduced to the students, guide them to independently design the circuit scheme to build a virtual circuit and simulate experiment, the designed circuit will be improved according to the experimental phenomena. By encouraging students to make analysis and summary for uncertainty and diversity of experimental results, students' comprehensive ability of finding problem and solving problem in circuit design has be enhanced.

Network equation method and the equivalent transformation method are the basic methods of circuit analysis, and expertly using the concept of mesh current, loop current and mesh current is the key of flexibly mastering circuit parameter calculation method and technique. Three basic circuit forms and their theoretical contents are shown in Fig. 2. In there, the concept of pharos and the Laplasse transform make it difficult for many students to understand and grasp by simply logical thinking. So, the process of theoretical derivation is quickly explained by using multimedia teaching means, the students' image thinking ability is mobilized by the animation form with VB visual program.

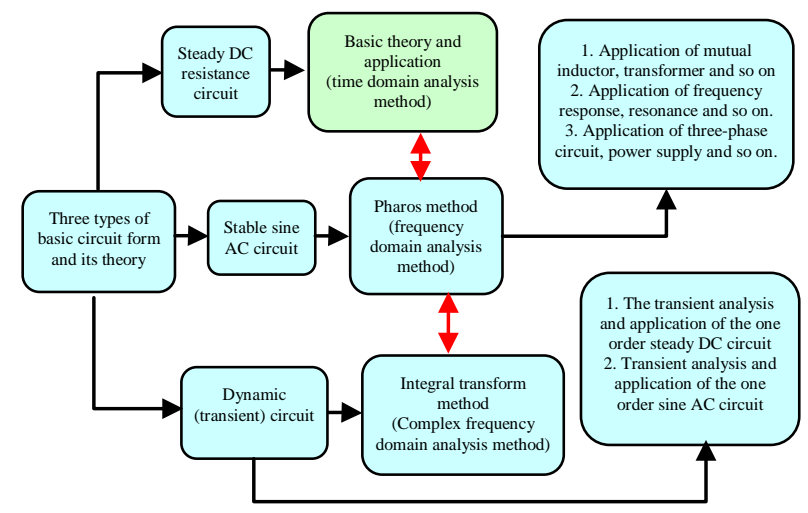

Fig. 2. Three types of basic circuit forms and theoretical structure

\section{B. Teaching method of training engineering practice ability}

In the university stage, the circuit is composed of a number of components, it may also contain a number of power 
supplies, and the components are combined in various ways, so the inductive analysis method is no longer applicable. The first step of the analysis method from perceptual to rational is to establish the reference direction of current and voltage. However, some of the students follow the concept of secondary school, used to think that the voltage source can only be the output current. Take the charging and discharging process of mobile phone as example, help student to understand that voltage source is also possible to absorb the power, in this case the current is flowing into the voltage source. After defining the reference direction of the voltage source current, the positive or negative value of the current is the embodiment of the release or absorption of electrical energy of the voltage source. Thevenin's theorem reflects the black box modeling thought, through learning, inspire and guide students to refine deep thinking connotation of electronic engineers in the functional design. In the time domain analysis of dynamic circuit, the application of the transient response to the simple ignition circuit is used to stimulate the students' learning interest. Three phase circuit is an important part of power electronic technology, and its circuit theory and analysis method is the basis of three-phase rectifier circuit and inverter circuit, and it is the important foundation of power generation system. By introducing the concept of the inverter circuit and the rectification circuit, guide the students to contact the engineering practical circuit, and stimulate their interest in learning.

The teaching is not only easy to understand but also to be logical, in order to cultivate students' creative thinking ability. From Fig. 2, we can see that three examples of practical applications in the analysis of stable sine AC circuit based on pharos method. The examples are the application of mutual inductor, transformer and so on, the application of frequency response, resonance and so on, and the application of threephase circuit, power supply and so on. Each is related to the major industries in the national economy, should be discussed in combination with application examples.

Fig. 2 shows two examples of practical applications in the transient analysis of dynamic circuits. They are the transient analysis and application for the first-order steady DC circuit and that for the first-order sine AC circuit. They are widely used in the anti interference and improve the circuit performance and should be used in combination with application examples in the course of teaching.

Through the discussion of the application examples, the students can master the knowledge, know how the knowledge is applied to the practical engineering, cultivate the engineering application consciousness, train and improve the students' ability of engineering practice.

\section{Teaching method of cultivating creative thinking ability}

The relationship between the analysis methods for three types of basic circuit is shown Fig. 3. These analysis methods are not only compatible with each other and can be used to form ideas of other physical processes. Similar ideas are also used in the course of teaching for other circuits such as the two port network theory. The teaching is not only easy to understand but also to be logical, to cultivate students' creative thinking ability.

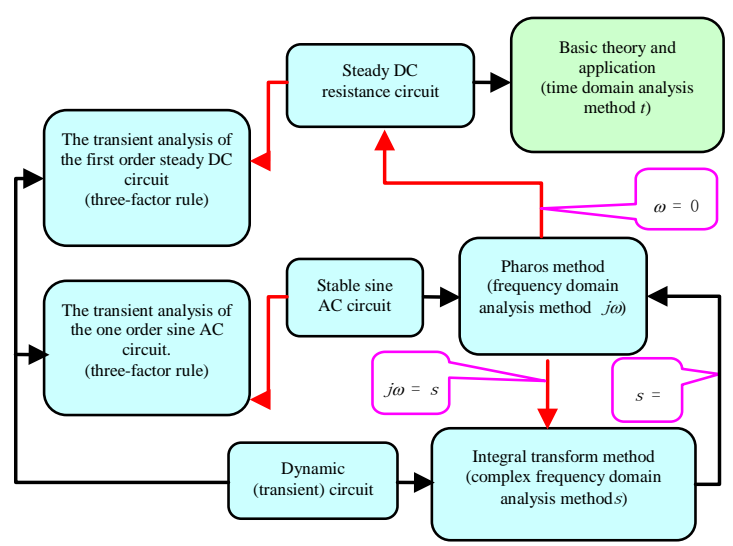

Fig. 3. The relationship between the analysis methods for three types of basic circuit

\section{Teaching Mode of TAKIng StUdents as the MaIN BODY}

In the course of education, teachers' teaching is the external cause of educational activities, and the students are the main cause and subjects. ${ }^{[6]}$ In the process of teaching of circuit course, each teacher should take the student as the main body, guide them to understand and master the thinking process of knowledge, stimulate their learning as consciousness, encourage them to think actively, train their ability to discover problems, access to information, and solidify cooperation, develop their the self learning ability using basic logic analysis method to solve the problem, cultivate their habits of self exploration for knowledge, train their scientific thinking methods, and improve their engineering quality.

For instance, the teaching process in class examples can be carried out as follows: First, show the content of the problem to the students and give a few minutes to let them think independently, read and analysis the problem, guide them to list all the knowledge points associated with this problem. Second, in the discussion of these knowledge points, review, digest, and comprehend the relationship between them, find one or more possible problem-solving ideas, lead students to be deduced and experience the complete solution process for each kind of ideas. Later, summarize the methods to solve this kind of problem. After that, given the same type of problem, divide the students into groups, demand each group of students to solve this problem with different problem-solving ideas, develop the discussions between different groups, summarize the advantages and disadvantages of each problemsolving ideas and the application experience of related knowledge, find the best solution path of this kind of problem, make students learn to think, mobilize their enthusiasm and participation.

\section{CONCLUSIONS}

In this paper, aiming at the theoretical teaching for the circuit course, the teaching reform program of the exploration 
and practice on the teaching method of circuit theory course based on the cultivation of innovation ability has put forward. The teaching of the circuit is divided into four parts, that is, basic knowledge, basic theory, basic circuit form and analysis methods, and extension theory. Adopt the student-centered teaching mode, apply the flexible and diverse teaching method and the various forms teaching measure, develop students' image thinking ability, help students to quickly and better grasp the circuit knowledge, train students' engineering practice ability and innovative thinking ability.

\section{REFERENCES}

[1] Kong Fanxin, Cha Guangcheng, Wu Mengling. To project certification and audit assessment as an opportunity to comprehensively deepen the comprehensive reform of professional. Journal of Higher Education, 2015(18), pp.65 66. (In Chinese)

[2] Li Ying. Innovation research and practice of College Students' engineering practice ability training under the background of engineering certification . Henan Chemical Industry, 2014(8), pp.59 61. (In Chinese)
[3] Geng Sujun, Yu Jian. The reform and practice of the "circuit" course for the applied undergraduate electrical engineering. China Electric Power Education, 2014(11), pp.71 72. (In Chinese)

[4] Qiu Guanyuan, Luo Xianjue. Circuit (the 5th Edition). Beijing: Higher Education Press, 2006. (In Chinese)

[5] Zhang Jiaolong, Zhang Wei, Han Sumin. Cultivation of innovative thinking in the teaching of "circuit" under the background of Engineering. China Electric Power Education, 2012(22). (In Chinese)

[6] Wang Zhuping. Teaching reform and practice of circuit course in universities and Colleges [J]. China Higher Education Research, 2005(6). (In Chinese)

[7] Wu Xia, Pan Lan. The Reform of Circuit and Electronic Technology Experiment Series [J]. Journal of Electrical \& Electronic Education, 2004(6). (In Chinese)

[8] Zhuang Guozhen. Action oriented teaching system in Higher Vocational Education [M]. Zhenjiang: Jiangsu University press, 2008. (In Chinese)

[9] Shi Yanhui, Wang Xiaoping, Gao Meng. Exploration and Practice on the teaching reform of the course of "circuit" [J]. Educational Research, 2010(10). (In Chinese)

[10] Zhan Xisheng, Wu Jie. Discussion on improving the teaching quality of "circuit" course [J]. China Electric Power Education, 2012(3). (In Chinese) 